\title{
NATIONAL PERSONALITY AND TIPPING CUSTOMS
}

\author{
Michael Lynn \\ School of Hotel Administration \\ Cornell University
}

In (2000) Personality and Individual Differences, 28, 395-404. 
Acknowledgements: The author would like to thank Tony Simons for helpful conversations and suggestions throughout the preparation of this manuscript. Request reprints from: Michael Lynn, 531 Statler Hall, School of Hotel Administration, Cornell University, Ithaca, NY 148536902, (607)255-8271, WML3@,Cornell.edu.

\begin{abstract}
This study examined the relationship between the number of tipped professions and national levels of extraversion, neuroticism and psychoticism in a sample of 21 countries. After two significant outliers were deleted, a simultaneous multiple regression analysis indicated that the number of tipped professions increased with national levels of extraversion and neuroticism and decreased with national levels of psychoticism. These findings are discussed in terms of their implications for: (1) the functions and underlying causes of a unique socialcustom/economic-institution, (2) the validity of the EPQ as a measure of national personality, and (3) the breadth of phenomena that are influenced by personality traits.
\end{abstract}




\section{NATIONAL PERSONALITY AND TIPPING CUSTOMS \\ INTRODUCTION}

Consumers around the world give voluntary sums of money (or tips) to workers after

those workers have performed services for them. Among the service workers commonly tipped are bartenders, busboys, casino croupiers, chambermaids, cocktail servers, concierges, doormen, maitre-d's, musicians, parking valets, porters, taxicab drivers, tour guides, ushers, waiters, washroom attendants and wine stewards (see Star, 1988). However, not all of these service workers are tipped in every country. In fact, there are vast differences across countries in the number of service professions it is customary to tip. In some countries, like Egypt and the United States, it is customary to tip many different service professions, while in other countries, like Denmark and New Zealand, it is customary to tip only a few service professions.

In an effort to better understand the functions and underlying causes of this social custom, researchers have begun to study predictors of the national differences in how many professions it is customary to tip (hereafter referred to as "the prevalence of tipping"). A series of studies (Lynn 1994, 1997; Lynn, Zinkhan and Harris, 1993) has found that tipping is more prevalent in countries to the extent that the people in those countries:

(1) regard power and status differences as legitimate and acceptable [measured by Hofstede's (1983) power distance index],

(2) feel threatened by, and attempt to avoid, ambiguous and uncertain situations [measured by Hofstede's (1983) uncertainty avoidance index],

(3) possess a collectivist mentality that emphasizes group membership and loyalty over autonomy and individuality [measured by Hofstede's (1983) individualism index], 
(4) embrace masculine values such as achievement and materialism over feminine values such as relationships and service [measured by Hofstede's (1983) masculinity index],

(5) have high levels of anxiety [measured by factor scores from Lynn and Hampson's (1975) analysis of demographic indices such as national rates of alcoholism and suicide], and

(6) value the esteem and recognition of others [measured by national averages on these values reported by Gordon (1976) and Haire, Ghiselli \& Porter (1966)].

This paper reports another study examining predictors of national differences in the prevalence of tipping. National levels of extraversion $(\mathrm{E})$, neuroticism $(\mathrm{N})$ and psychoticism $(\mathrm{P})$, as measured by average scores on the Eysenck Personality Questionnaire (EPQ), were correlated with the number of tipped professions in a sample of 21 countries. This was exploratory research without apriori hypotheses. However, reasons for believing that the prevalence of tipping might be related to national scores on these personality traits are described below.

Tipping may be more widespread in countries with extraverted populations than in countries with introverted populations, because extraverts are likely to value the social functions of tipping to a greater extent than introverts. Tipping is supposed to function as: (1) an incentive for servers to provide greater attention to their customers (Bodvarsson \& Gibson, 1994; Hemenway, 1984; Lynn \& Simons, In Press), (2) an expression of satisfaction/dissatisfaction with service (Ford, 1980; Lynn \& Graves, 1996; Schein, Jablonski \& Wohlfarhrt, 1984), and (3) a form of conspicuous consumption or status display (Lynn, 1997; Paules, 1991; Shamir, 1984). These social functions of tipping should appeal to extraverted (i.e., social, expressive and dominant) individuals more than to introverted individuals. Thus, high levels of national extraversion may increase the prevalence of tipping. 
Tipping may also be more widespread in countries with high $\mathrm{N}$ scoring populations than in countries with emotionally stable populations. Tipping provides service workers with an incentive for delivering good service, which increases consumers' confidence that they will be treated in a friendly and professional way (Lynn, 1994; Mills \& Riehle, 1987; Shein, et al, 1984). This assurance should appeal to high $\mathrm{N}$ scoring people, who tend to be anxious and nervous (Eysenck \& Eysenck, 1985), more than to emotionally stable people. Thus, high levels of national neuroticism may increase the prevalence of tipping.

Finally, the prevalence of tipping may be either positively or negatively related to national levels of psychoticism. Tipping is considered by some to be an anti-social behavior that degrades and insults servers (Hemenway, 1984; Scott, 1916; Seagrave, 1998) and is considered by others to be a pro-social behavior that benefits servers (Cunningham, 1979; Speer, 1997). If the anti-social view of tipping is dominant, then high P scoring (i.e., aggressive, anti-social and unempathic) people should like and support tipping more than low P scoring (i.e., warm, caring and empathic) people. If the pro-social view of tipping is dominant, then the reverse should be true.

\section{METHOD}

\section{Independent Variables}

Measures of national levels of extraversion, neuroticism and psychoticism were obtained from Lynn and Martin (1995). These authors compiled information from several sources (most notably from Barrett \& Eysenck, 1984) and reported average EPQ scores on the three personality traits for each of 37 nations. The national averages reported by these authors were used as predictor variables in this study. 


\section{Dependent Variable}

A measure of national differences in the prevalence of tipping was obtained from Nancy Star's (1988) International Guide to Tipping. The number of 33 different service professions that are customarily tipped in each of 32 non-communist countries were added up and the sum was used as the dependent variable in this study. This is the same source of information and measure of tipping's prevalence used by Lynn, et al (1993). However, this study includes measures of tipping's prevalence for two countries not included in Lynn, et al's sample - i.e., Egypt and Iceland.

\section{$\underline{\text { Sample }}$}

Data on both the independent and dependent measures used in this study were available for 21 countries - Australia, Brazil, Canada, Egypt, Finland, France, Germany, Great Britain, Greece, Hong Kong, Iceland, India, Israel, Italy, Japan, Mexico, the Netherlands, Norway, Portugal, Spain and the United States of America. All of these 21 countries were included in the study sample before significant outliers were detected and deleted.

\section{RESULTS}

\section{Analysis of Entire Sample}

The relationships between the prevalence of tipping and national levels of extraversion, neuroticism and psychoticism are shown in Figures 1 through 3. Among all 21 countries, the number of tipped professions correlated at $\mathrm{r}=.32(\mathrm{p}<.20)$ with national extraversion, at $\mathrm{r}=.32$ $(\mathrm{p}<.20)$ with national neuroticism, and at $\mathrm{r}=.02(\mathrm{p}<.50)$ with national psychoticism. A simultaneous multiple regression of the number of tipped professions on national levels of extraversion, neuroticism and psychoticism produced a model $\mathrm{R}^{2}$ of $29 \%(\mathrm{~F}(3,17)=2.34, \mathrm{p}<$ 
$.11)$ as well as a significant regression coefficient for national neuroticism $($ Beta $=.49, \mathrm{t}(17)=$ $2.15, \mathrm{p}<.05)$, a marginally significant regression coefficient for national extraversion (Beta $=$ $.44, t(17)=2.08, \mathrm{p}<.06)$, and a non-significant regression coefficient for national psychoticism $(\operatorname{Beta}=.20, t(17)=-.90, p<.39)$. However, this analysis included two countries (i.e., Iceland and Japan) that appeared in Figures 1 through 3 to be outliers, so additional analyses were performed as described below.

\section{$\underline{\text { Identification of Outliers }}$}

Rousseeuw and Leroy's (1987) software program "PROGRESS" was used to identify any significant, multivariate outliers in the study sample. This program performs a robust regression analysis using Rousseeuw's (1984) least median of squares method and calculates standardized residuals from the robust regression line. When this program was used to regress the number of tipped professions on national levels of extraversion, neuroticism and psychoticism in the entire sample of 21 countries, four countries emerged as having large standardized residuals - Australia $($ residual $=2.64)$, Canada $($ residual $=2.63)$, Iceland $($ residual $=$ -6.72) and Japan (residual $=-5.53$ ). Given the small sample of countries in this study, only those countries whose standardized residuals exceeded a value of 3.0 (i.e., Iceland and Japan) were deleted from the sample as significant outliers.

Japan has emerged as an outlier in other research on the prevalence of tipping (Lynn, 1994; Lynn, et al, 1993), so its status as an outlier in this study is probably not due to problems with the study's measurement of the independent variables. Apparently, some factor not included in the regression models of this or previous research reduces the number of tipped professions in Japan. Lynn (1994; Lynn, et al, 1993) suggests that this unmodeled factor may be 
the extreme emphasis the Japanese place on repaying favors and debts. "The need to repay favors and debts is so strong in Japan that the Japanese try to avoid becoming enmeshed in the complications of reciprocation with strangers (Benedict, 1946). Tipping entails just such complications... (Lynn, 1994, pg.138).”

Iceland has not been included in previous research on the prevalence of tipping, so there is less information with which to explain its status as an outlier than was the case with Japan. Perhaps there are problems with the national personality scores for Iceland. Another possibility is that factors not included in the study's regression model cause the lower than predicted number of tipped professions in Iceland. Hopefully, future research will shed light on this issue. Analysis of Sample Without Outliers

Among the 19 countries in the sample from which significant outliers had been deleted, the number of tipped professions correlated at $\mathrm{r}=.32(\mathrm{p}<.20)$ with national extraversion, at $\mathrm{r}=$ $.56(\mathrm{p}<.02)$ with national neuroticism, and at $\mathrm{r}=.06(\mathrm{p}<.80)$ with national psychoticism. More importantly, a simultaneous multiple regression of the number of tipped professions on national levels of extraversion, neuroticism and psychoticism in this sample produced a model $\mathrm{R}^{2}$ of $62 \%$ $(\mathrm{F}(3,15)=8.08, \mathrm{p}<.005)$ along with significant regression coefficients for national levels of extraversion $($ Beta $=.50, t(15)=3.03, \mathrm{p}<.01)$ neuroticism $($ Beta $=.77, \mathrm{t}(15)=4.45, \mathrm{p}<.001)$ and psychoticism $($ Beta $-.40, \mathrm{t}(15)=2.28, \mathrm{p}<.04)$.

\section{DISCUSSION}

The results of this study indicated that national levels of extraversion, neuroticism and psychoticism each made unique contributions to the prediction of the number of tipped professions in a sample of 19 countries. When national differences in the other personality traits 
were statistically controlled, the prevalence of tipping increased with national levels of extraversion and neuroticism and decreased with national levels of psychoticism. These findings are important because they shed light on: (1) the functions and underlying causes of a unique social-custom/economic-institution, (2) the validity of the EPQ as a measure of national personality, and (3) the breadth of phenomena that are influenced by personality traits. Each of these points is discussed below.

\section{Functions and Underlying Causes of Tipping}

This study demonstrates that national personality traits are related to variations in at least one dimension of national tipping customs - i.e., the number of tipped professions. The data is correlational, so it does not permit strong causal inferences. However, it seems doubtful that tipping customs influence national personality. Tipping customs become personally relevant to consumers only when they begin buying and paying for various services. This usually doesn't occur until late adolescence or early adulthood, by which time personality traits are largely set (Eysenck \& Eysenck, 1985). Even when consumers are personally responsible for following tipping customs, those customs are not central to consumers' identities, lives and belief systems as (for example) religious customs are. Thus, it is implausible that tipping customs impact consumer's psyche's in any meaningful, long-term ways. More plausible is the idea that national personality traits influence the development and spread of tipping customs.

National extraversion. Tipping was more prevalent in countries with extraverted populations than in countries with introverted populations. This relationship is consistent with the idea that national extraversion increases the prevalence of tipping because tipping provides social benefits that appeal to extraverts more than to introverts. Tipping is supposed to: (1) encourage servers to be more customer-oriented (Bodvarsson \& Gibson, 1994; Lynn \& Simons, 
In Press), (2) allow customers to express their satisfaction/dissatisfaction with service (Ford, 1980; Lynn \& Graves, 1996), and (3) give customers an opportunity to display their wealth/status (Lynn, 1997; Shamir, 1984). Extraverts are more social and expressive than are introverts (Eysenck \& Eysenck, 1985), so extraverts should value these benefits (especially the attention and royal-treatment that tipping motivates servers to provide) more than do introverts.

Supporting the idea that the prevalence of tipping is affected by national differences in the value placed on tipping's social benefits is a recent study by Lynn (1997). He found that the number of tipped professions was positively related to Gordon's (1976) national scores on the desire for recognition - i.e., "being looked up to and admired, being considered important, attracting favorable notice, achieving recognition (Gordon, 1976, pg. 1)”. National extraversion and national desire for recognition are correlated with one-another $(\mathrm{r}=.72, \mathrm{n}=13, \mathrm{p}<.006)$ and both are positively related to the prevalence of tipping. Together, these predictors of the number of tipped professions suggest that the level of desire for social attention and esteem may positively affect the prevalence of tipping.

National neuroticism. Tipping was more prevalent in countries with high $\mathrm{N}$ scoring populations than in countries with emotionally stable populations. This relationship is consistent with the idea that national neuroticism increases the prevalence of tipping because tipping helps calm consumer's anxieties about being served by strangers. Tipping is supposed to be an incentive/reward for good service (Bodvarsson \& Gibson, 1994; Lynn \& Graves, 1996) and surveys indicate that consumers believe the practice of tipping does improve service (Mills, \& Riehle, 1987; Schein, et al., 1984). Tipping has also been theorized to be a form of sharing designed to reduce service worker's envy of their customers (Foster, 1972; Lynn, 1994). Neurotics tend to be anxious and nervous (Eysenck \& Eysenck, 1985), so high N scoring people 
may take more comfort from tipping's role as an inducement for servers to be courteous, friendly and service-oriented than do emotionally stable people.

Consistent with this "anxiety" explanation for the relationship between national neuroticism and the prevalence of tipping are two studies finding that the number of tipped professions is positively correlated with national levels of anxiety (Lynn, 1997), and uncertainty avoidance (Lynn, et al, 1993). Furthermore, national neuroticism scores were moderately related to Lynn and Hampson's (1975) anxiety scores $(\mathrm{r}=.48, \mathrm{n}=11, \mathrm{p}<.14)$ and Hofstede's (1983) uncertainty avoidance scores $(\mathrm{r}=.33, \mathrm{n}=19, \mathrm{p}<.17)$ in this study's sample of countries. The convergence of results from three studies using three different measures of national anxiety/neuroticism and three different (though overlapping) samples of nations strongly suggests that one of the chief functions of tipping is to reduce consumers' anxieties about having strangers serve them.

National psychoticism. After controlling for national extraversion and neuroticism, the prevalence of tipping was negatively related to national psychoticism. This relationship is consistent with the idea that psychoticism reduces the prevalence of tipping because high $\mathrm{P}$ scoring people are less eager to give monetary gifts to servers than are low P scoring people. Tipped employees usually receive very low wages and many consumers tip in order to make-up for this fact (Speer, 1997). High P scoring people tend to be aggressive, anti-social and unempathic, so they should be less willing to supplement server's incomes than are low P scoring people.

Interestingly, the effects of national psychoticism on tipping are opposite to the effects of national masculinity reported by Lynn et al (1993). This observation is notable because national psychoticism is positively correlated with Hofstede's (1983) index of national masculinity $(r=$ 
$.46, \mathrm{n}=19, \mathrm{p}<.05)$ in the current study sample. Hofstede's masculinity index reflects "the extent to which the dominant values in society are 'masculine' - that is, assertiveness, the acquisition of money and things and not caring for others, the quality of life or people (Hofstede, 1980, pg46)." National psychoticism reflects anti-social tendencies that are closely related to the masculine disdain for caring, quality of life and people. The fact that these two positively related constructs have opposite relationships to the prevalence of tipping is instructive. Specifically, these relationships suggest that it is the value placed on assertiveness, achievement and materialism, rather than the disdain for caring, quality of life and people, that is responsible for the positive relationship between masculinity and the prevalence of tipping. This is a different interpretation of the masculinity effect than that provided by Lynn, et al (1993). In addition, these relationships suggest that the negative effects of disdain for caring, quality of life and people are weaker than the positive effects of valuing assertiveness, achievement and materialism. Otherwise, Hofstede's masculinity index, which measures both sets of values, would not be positively related to the prevalence of tipping. This latter suggestion is also consistent with the relatively weak effects of psychoticism that emerged only after statistically controlling for extraversion and neuroticism.

Validity of National EPQ Scores

The Eysenck Personality Questionnaire was designed to measure the three major dimensions of personality - extraversion, neuroticism and psychoticism. This instrument has been validated as an individual difference measure and has been shown to have comparable factor structures across different countries (Barrett \& Eysenck, 1984; Eysenck \& Eysenck, 1985). However, its validity as a measure of national differences in personality is less well established. Relationships between variables (or between scale items) can differ at different 
levels of aggregation (Ostroff, 1993) so national averages on the extraversion, neuroticism and psychoticism scales of the EPQ may not reflect the same underlying constructs that individual's scores on these scales do. Lynn and Martin (1995) have provided some evidence for the predictive validity of national averages on EPQ personality traits by demonstrating that these national averages correlate with relevant measures of national values and other statistics like the rates of suicide and alcoholism. The present study adds to this small body of evidence about the validity of national personality scores based on the EPQ. The fact that national averages on the extraversion, neuroticism and psychoticism scales of the EPQ each made unique and theoretically intelligible contributions to the prediction of the number of tipped professions provides further evidence that the scales used to measure these traits are valid at the national, as well as the individual, level of analysis.

Breadth of Personality Traits' Effects

Personality traits have long been used to predict and understand the behavior of individuals (Eysenck \& Eysenck, 1985). In recent years, they have also been used to predict and/or understand national statistics such as alcoholism and suicide rates and national levels of economic productivity (Lynn, 1971, 1991; Lynn \& Hampson, 1975; Lynn \& Martin, 1995). The present study is part of a series (see Lynn 1994,1997) that extends the domain of quantitative personality research even further - to the prediction and understanding of an interesting social and economic institution. Hopefully, this work will encourage future researchers to investigate the effects of national character (or personality traits) on other social and economic institutions. 


\section{REFERENCES}

Barrett, P. \& Eysenck, S. (1984). The assessment of personality factors across 25 countries. Personality and Individual Differences, $\underline{5}$, 615-632.

Benedict, R. (1946). The chrysanthemum and the sword. New York: Free Press.

Bodvarsson, O.B. \& Gibson, W.A. (1994). Gratuities and customer appraisal of service: evidence from Minnesota restaurants. The Journal of Socio-Economics, 23, 287-302.

Cunningham, M.R. (1979). Weather, mood and helping behavior: Quasi-experiments with the sunshine samaritan. Journal of Personality and Social Psychology, 37, 1947-1956.

Eysenck, H.J. \& Eysenck, M.W. (1985). Personality and individual differences: A natural science approach. New York: Plenum Press.

Ford, C. (1980). Charlotte Ford's Book of Modern Manners, New York: Simon and Schuster. Foster, G.M. (1972). The anatomy of envy: A study of symbolic behavior. Current Anthropology, 13, 165-186.

Gordon, L.V. (1976). Survey of Interpersonal Values: Revised Manual. Chicago: Science Research Associates.

Haire, M., Ghiselli, E.E. \& Porter, L.K. (1966). Managerial Thinking: An International Study. John Wiley: New York.

Hemenway, D. (1984). Prices and Choices: Microeconomic Vignettes. Cambridge, MA: Ballinger.

Hofstede, G. (1980). Motivation, leadership and organization: Do American theories apply abroad? Organizational Dynamics (Summer), 42-63. 
Hofstede, G. (1983). National cultures in four dimensions: A research-based theory of cultural differences among nations. International Studies of Management and Organization, $\underline{8}$, $46-74$.

Lynn, M. (1994). Neuroticism and the prevalence of tipping: A cross-country study. Personality and Individual Differences, 17, 137-138.

Lynn, M. (1997). Tipping customs and status seeking: A cross-country study. International

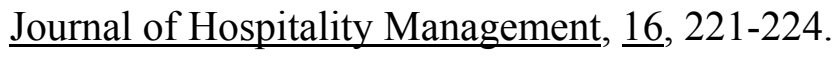

Lynn, M. \& Graves, J. (1996). Tipping: An incentive/reward for service? Hospitality Research Journal, 20, 1-14.

Lynn, M. \& Simons, T. (In Press). Predictors of male and female server's average tip earnings. Journal of Applied Social Psychology.

Lynn, M.; Zinkhan, G.M. \& Harris, J. (1993). Consumer tipping: A cross-country study. Journal of Consumer Research, 20, 478-488.

Lynn, R. (1971). Personality and National Character, Oxford: Pergamon Press.

Lynn, R. (1991). The Secrets of the Miracle Economy, London: The Social Affairs Unit.

Lynn, R. \& Hampson, S.L. (1975). National differences in extraversion and neuroticism. British Journal of Social and Clinical Psychology, 14, 223-240.

Lynn, R. \& Martin, T. (1995). National differences for thirty-seven nations in extraversion, neuroticism, psychoticism and economic, demographic and other correlates. Personality and Individual Differences, 19 , 403-406.

Mills, S. \& Riehle, H. (1987). What customers think about tips vs. service charges. Restaurants USA,, , 20-22. 
Ostroff, C. (1993). Comparing correlations based on individual-level and aggregated data. Journal of Applied Psychology, 78, 569-582.

Paules, G.F. (1991). Dishing It Out: Power and Resistance Among Waitresses in a New Jersey Restaurant. Philadelphia: Temple University Press.

Rousseeuw, P. (1984). Least median of squares regression. Journal of the American Statistical Association, $79,871-880$.

Rousseeuw, P. \& Leroy, A. (1987). Robust Regression and Outlier Detection, New York: Wiley.

Schein, J.E.; Jablonski, E.F. and Wohlfarhrt, B.R. (1984). The Art of Tipping: Customs and Controversies, Wausau, WI: Sun Press.

Scott, W.R. (1916). The Itching Palm: A Study of the Habit of Tipping in America. Philadelphia: The Penn Publishing Co.

Seagrave, K. (1998). Tipping: An American Social History of Gratuities. Jefferson, NC: McFarland \& Co.

Shamir, B. (1984). Between gratitude and gratuity: An analysis of tipping. Annals of Tourism, 11, 59-78.

Speer, T.L. (1997). The give and take of tipping. American Demographics, (February), 51-54. Star, N. (1988). The International Guide to Tipping. New York: Berkeley Books. 